\title{
Susceptibilidade de larvas de Cerotoma arcuata Olivier (Coleoptera: Chrysomelidae) a Beauveria bassiana (Bals.) Vuillemin, Metarhizium anisopliae (Metsch.) Sorokin e Bacillus thuringiensis Berliner
}

\author{
Susceptibility of Cerotoma arcuata Olivier (Coleoptera: Chrysomelidae) larvae to Beauveria bassiana \\ (Bals.) Vuillemin, Metarhizium anisopliae (Metsch.) Sorokin and Bacillus thuringiensis Berliner
}

\author{
Maria Lucia França Teixeira' ${ }^{\mathrm{I}}$ Avílio Antonio Franco ${ }^{\mathrm{II}}$
}

\section{RESUMO}

Larvas de 2 o instar de Cerotoma arcuata foram avaliadas em relação à susceptibilidade aos fungos entomopatogênicos Beauveria bassiana, Metarhizium anisopliae e a bactéria Bacillus thuringiensis com as toxinas Cry3. Os insetos adultos foram mantidos em gaiolas $e$ alimentados com plântulas de feijão (Phaseolus vulgaris L.) $e$ as larvas em "gerbox" com cotilédones de plântulas de feijão recém-germinadas. Das oito estirpes de B. bassiana avaliadas, CG 156 e CG 213 causaram 100\% de mortalidade das larvas, as duas estirpes de M. anisopliae CG 210 e CG 321 foram patogênicas, eliminando 80 e 100\% das larvas de C. arcuata, $e$, das cinco estirpes de $\boldsymbol{B}$. thuringiensis testadas, o isolado CG 940 causou $70 \%$ de mortalidade das larvas.

Palavras-chave: vaquinha, fungos entomopatogênicos, äendotoxina, controle biológico.

\section{ABSTRACT}

Second instar larvae of Cerotoma arcuata were evaluated concerning the susceptibility to fungi Beauveria bassiana and Metarhizium anisopliae and Bacillus thuringiensis strains containing Cry3 toxin. Adults of $\mathbf{C}$. arcuata were kept in large cages and fed on bean seedlings and the larvae were reared in 'gearbox' feeding on germinated Phaseolus bean cotyledons. Strains CG 156 and CG 213 of B. bassiana killed $100 \%$ of the insect larvae and strains CG 210 and CG 321 of M. anisopliae killed 80 and $100 \%$ of the insect larvae. Strain CG 940 of B. thuringiensis killed $70 \%$ of the insect larvae.

Key words: bean leaf beetle, entomopathogenic fungi, äendotoxin, biological control.

\section{INTRODUÇÃO}

Cerotoma arcuata Olivier é um crisomelídeo desfolhador de leguminosas comestíveis como soja (Glycine max (L.) Merril), feijão (Phaseolus vulgaris L.) e caupi (Vigna unguiculata (L.) Walp.). Devido à desfolha e à redução da capacidade fotossintética provocada pelos adultos, menos importância é dada aos danos causados por sua fase larval. Entretanto, as larvas do inseto alimentam-se de sementes em germinação, nódulos, raízes e da região do coleto (QUINTELA et al., 1991), podendo causar o tombamento e a morte de plântulas e, assim como os adultos, transmitir microorganismos fitopatogênicos, como o vírus do mosaico severo do caupi (SALAS et al., 1999). Quando a cultura obtém o nitrogênio através da simbiose com o rizóbio, comum em leguminosas, os danos se tornam mais graves. Larvas de C. arcuata, ao destruírem os nódulos onde a fixação biológica ocorre, acarretam perdas de até $25 \%$ na produção de grãos de feijoeiro no campo (TEIXEIRA, 1993) e de 45\% em casa de vegetação (TEIXEIRA et al. ,1996). Em soja no campo, larvas de $\boldsymbol{C}$. trifurcata (Förster) provocaram a redução de até $45 \%$ na fixação de $\mathrm{N}_{2}$ (LAYTON, 1983). Em casa-de-vegetação, parâmetros relativos à fixação biológica de nitrogênio e ao crescimento foram reduzidos pela infestação de 30 larvas de $\boldsymbol{C}$. arcuatus Olivier por planta (NAVA et al., 2003).

O controle biológico de $\boldsymbol{C}$. arcuata pela susceptibilidade a microorganismos ocorre naturalmente, quando os fatores ambientais são favoráveis. Nestas ocasiões, estirpes de fungos entomopatogênicos como B. bassiana (Bals.) Vuillemin podem ser isoladas de adultos de $\boldsymbol{C}$. arcuata encontrados em plantações, como conduzido por YAGINUMA et al. (1994) em soja no Cerrrado.

\footnotetext{
ILaboratório de Fitossanidade, Instituto de Pesquisas Jardim Botânico do Rio de Janeiro. Rua Jardim Botânico, 1008, 22460-170, Rio de Janeiro, RJ, Brasil. E-mail: malu@jbrj.gov.br.

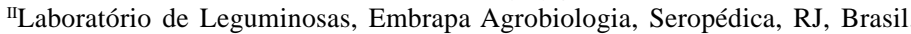


Por meio de bioensaios com $\boldsymbol{B}$. bassiana, LORD et al. (1987) verificaram que, apesar de o fungo ter sido letal ao adulto, o patógeno não contribuiu para a diminuição significativa da redução dos danos causados pelo inseto, assim como da oviposição e da viabilidade dos ovos. Por outro lado, devido à importância dos danos provocados pelas larvas do inseto, foi realizada tentativa de controle no solo e em sementes, utilizando-se conídios de $\boldsymbol{B}$. bassiana e $\boldsymbol{M}$. anisopliae (Metsch.) Sorokin (SÁ et al., 1989; QUINTELA et al., 1990), apresentando, nesse estágio, alta susceptibilidade aos patógenos.

A família Chrysomelidae possui várias espécies de coleópteros susceptíveis à bactéria $\boldsymbol{B}$. thuringiensis Berliner, destacando-se: Leptinotarsa decemlineata (Say) (COOPER, et al., 2004) e Diabrotica virgifera virgifera Le conte. (MOELLENBECK et al., 2001). A associação do fungo B. bassiana e da bactéria B. thuringiensis tem sido testada contra vários insetos, geralmente sem interação significativa (KRIEG, 1971). Isoladamente, a bactéria $\boldsymbol{B}$. thuringiensis foi utilizada com sucesso no controle da infestação por adultos e larvas de $\boldsymbol{C}$. ruficornis Olivier na cultura de batata (Solanum tuberosum L.), com taxa de mortalidade de até $100 \%$ após 72 horas (AMBANG et al., 2002).

$\mathrm{O}$ presente trabalho teve como objetivo avaliar em laboratório a susceptibilidade de larvas de $2^{2}$ instar de $\boldsymbol{C}$. arcuata às estirpes de $\boldsymbol{B}$. bassiana, $\boldsymbol{M}$. anisopliae e $\boldsymbol{B}$. thuringiensis isoladas de Cerotoma sp. e/ou de outros crisomelídeos.

\section{MATERIAL E MÉTODOS}

Adultos de $\boldsymbol{C}$. arcuata coletados manualmente em lavoura de feijão localizada no Campo Experimental da Embrapa-Agrobiologia foram dispostos em gaiolas confeccionadas em madeira e tela de “nylon”, em ambiente sob temperatura de $26 \pm 1^{\circ} \mathrm{C}$, fotofase de 14 horas e umidade relativa (UR) de $70 \pm$ $20 \%$.

Os insetos foram alimentados com plantas de feijão $\boldsymbol{P}$. vulgaris cv. “Carioca 80” crescidas em copos com vermiculita estéril por quinze dias e posteriormente transferidas para tubos de ensaio com água, onde foram fixadas com algodão na altura dos caules e trocadas semanalmente, evitando a reposição diária de folhas (CARDONA et al., 1982; RAJNAUTH et al., 1987; HEINECK \& CORSEUIL, 1995).

Como substrato para postura dos insetos, utilizou-se vermiculita estéril em placas de Petri revestidas por tecido preto, fino, do tipo "nylon" (ABREU NETO, 1999), para impedir a passagem dos ovos para a vermiculita, que foi mantida úmida para evitar o ressecamento desses ovos. Os tubos foram inclinados sobre as placas, de modo que a parte aérea das plântulas recobrisse toda a região de postura.

Os ovos foram retirados diariamente com o auxílio de um pincel, individualizados e transferidos para placas de Petri contendo duas camadas de papel de filtro umedecido, que permaneceram em ambiente sob temperatura de $27 \pm 1^{\circ} \mathrm{C}$, fotofase de 14 horas e UR de $70 \pm 20 \%$.

Avaliou-se o número de dias decorridos para a eclosão das larvas. As larvas neonatas foram transferidas com o auxílio de um pincel para caixas do tipo "gerbox", contendo papel de filtro úmido e feijão pré-germinado, sendo colocadas duas larvas por plântula, uma em cada cotilédone sem a casca.

As sementes de feijão foram previamente desinfestadas com uma solução de hipoclorito de sódio $1 \%$ e pré-germinadas durante seis dias em papel de germinação, em câmara incubadora. Os recipientes permaneceram tampados, em temperatura de $26 \pm 1^{\circ} \mathrm{Ce}$ UR de $70 \pm 20 \%$ em ausência de luz, simulando o ambiente natural das larvas no interior do solo, junto ao sistema radicular.

Para a medição do pH intestinal, importante para a ação das toxinas de $\boldsymbol{B}$. thuringiensis, utilizaramse larvas de $\boldsymbol{C}$. arcuata de 10 dias de idade. As mesmas larvas foram colocadas sobre lâminas de vidro, e submetidas a choque elétrico de 10 volts, utilizando-se um potenciômetro (Powerstar). Os eletrodos foram colocados sobre as porções central e final das larvas e, após a regurgitação, o líquido foi diluído em uma gota de água deionizada, sendo o seu $\mathrm{pH}$ medido com o auxílio de fita indicadora da marca Merck (SILVAWERNECK et al. ,1995).

Testes de patogenicidade

As estirpes de B. bassiana CG 218, CG 224

e as de M. anisopliae CG 210 e CG 321 foram isoladas de $\boldsymbol{C}$. arcuata. As estirpes de B. bassiana CG 61, CG 79, CG 156, CG 213, CG 225 e CG 253 de outros coleópteros da família Chrysomelidae foram todas provenientes da Embrapa Recursos Genéticos e Biotecnologia. Os isolados estocados em tubos de ensaio em meio BDA (batata-dextrose-ágar) foram repicados, suspensos em $1 \mathrm{ml}$ de água estéril e inoculados separadamente em erlenmeyers de $250 \mathrm{ml}$, contendo $50 \mathrm{~g}$ de arroz branco parboilizado e autoclavado com $30 \mathrm{ml}$ de água destilada por 30 minutos. Posteriormente, foram mantidos em câmara em temperatura de $26 \pm 1^{\circ} \mathrm{C}$ e fotofase de 12 horas por quatorze dias. Após o crescimento dos fungos, para separá-los do substrato, lavou-se o arroz com uma solução de água estéril de volume conhecido, contendo 
$0,1 \%$ de Tween $80^{\circledR}$, posteriormente filtrada em gaze estéril. Para calcular a concentração de conídios, uma amostra de cada suspensão foi diluída, seguindo-se a contagem direta em microscópio óptico com auxílio de uma câmara de Neubauer (ALVES \& MORAES, 1998). Para a viabilidade de conídios, cada amostra de suspensão foi diluída até a concentração de $10^{8}$ conídios $\mathrm{ml}^{-1}$, utilizando-se dez microlitros para incubação em placas com meio BDA, a $27 \pm 1^{\circ} \mathrm{C}$ por 18 horas. A contagem de esporos germinados foi feita através de leitura em microscópio óptico (ALVES \& MORAES, 1998), garantindo uma concentração mínima de $10^{10}$ conídios $\mathrm{ml}^{-1} \mathrm{e}$ viabilidade acima de $92 \%$.

Cada copo do tipo "coletor universal”, com fundo revestido de papel de filtro e autoclavado, recebeu duas plântulas de feijão recém-germinado, com uma larva de $2^{\underline{0}}$ instar por planta, sobre os cotilédones. Sobre as plântulas e as larvas, aspergiu-se, por meio de uma pipeta Pasteur com pêra, $1 \mathrm{ml}$ da suspensão e, para a testemunha, utilizou-se água destilada. Os copos foram fechados e mantidos a $27 \pm 1^{\circ} \mathrm{C}$, UR de $70 \%$ em ausência de luz, e avaliados após sete dias. Para cada tratamento com $\boldsymbol{B}$. bassiana, foram realizadas cinco repetições e com $\boldsymbol{M}$. anisopliae quatro repetições, sendo cada copo uma repetição.

Foram utilizadas quatro estirpes de $\boldsymbol{B}$. thuringiensis CG 904, CG 940, CG 946 e CG 948 provenientes da Embrapa Recursos Genéticos e Biotecnologia, selecionadas entre 50 estirpes através da técnica PCR (polymerase chain reaction), para identificação de duas subclasses de genes cry: cry3A e cry3B, ambas tóxicas para coleópteros (MARQUEZ, 1996). A estirpe CG 948 contém a proteína Cry3A, e as demais estirpes contém a proteína Cry3, mas não estão incluídas nas subclasses A ou B.

As estirpes foram repicadas de tubos de ensaio inclinados com meio Ágar Nutritivo para erlenmeyers de $250 \mathrm{ml}$ contendo $50 \mathrm{ml}$ de meio Caldo Nutritivo (ALVES, 1998). A seguir, os erlenmeyers foram incubados em “shaker” a $200 \mathrm{rpm} / 30^{\circ} \mathrm{C} / 48$ horas, quando foram feitas lâminas a fresco, e também lâminas coradas com Amido Black e/ou Coomassie Blue, para facilitar a visualização dos cristais. As lâminas foram observadas em microscópio óptico com e sem contraste de fase para verificar se as estirpes apresentavam grande quantidade de cristais e esporos e se havia contaminantes. Para o cálculo da concentração de esporos, uma amostra de cada suspensão foi diluída, seguindo-se a contagem direta em microscópio óptico com auxílio de uma câmara de Neubauer, assegurando o mínimo de $10^{10}$ esporos viáveis $\mathrm{ml}^{-1}$.

Cada copo do tipo "coletor universal”, com fundo revestido de papel de filtro e autoclavado, recebeu duas plântulas de feijão recém-germinado. As plântulas foram previamente imersas nas suspensões por uma hora e a testemunha em caldo nutritivo puro e receberam uma larva de $2^{\circ}$ instar por planta, sobre os cotilédones. Os copos foram fechados e estocados a $27 \pm 1^{\circ} \mathrm{C}$, UR de $70 \%$ e ausência de luz, e avaliados após sete dias. Para cada tratamento, utilizaram-se cinco repetições com dois indivíduos.

Os insetos mortos durante os experimentos por M. anisopliae e B. bassiana foram colocados em frascos individuais, mantidos em estufa a $27 \pm 1^{\circ} \mathrm{C}$ e examinados diariamente para avaliar a presença de micélio e a esporulação. Os insetos mortos no experimento com $\boldsymbol{B}$. thuringiensis foram lavados em água estéril antes da retirada de uma porção da hemolinfa, que foi diluída em $1 \mathrm{ml}$ de água estéril para verificação de esporos e cristais em microscópio (ALVES, 1998).

Os dados de porcentagem de mortalidade foram transformados para $\sqrt{\mathrm{x}+1}$ antes da análise estatística. A análise estatística constou de análise de variância seguida de comparação de médias pelo Teste de Tukey $(p=0,05)$.

\section{RESULTADOS E DISCUSSÃO}

O sistema de criação de $\boldsymbol{C}$. arcuata foi eficiente para produzir larvas de $2^{\circ}$ instar em quantidade suficiente para serem utilizadas nos bioensaios. $\mathrm{O}$ período de incubação de ovos foi de cinco a nove dias, em que maior porcentagem de eclosão de larvas tendeu a ser no sétimo dia, com uma média de 64,5\%, na mesma faixa observada por HEINECK \& CORSEUIL (1995) e RAJNAUTH et al. (1987).

Foram obtidos nos bioensaios altos níveis de mortalidade pela inoculação com estirpes dos fungos, confirmada pelo crescimento de micélio e esporulação após a morte dos insetos (Figuras 1 e 2). Dentre os oito isolados de $\boldsymbol{B}$. bassiana avaliados, as estirpes CG 156, CG 213 foram eficientes no controle de larvas de $\boldsymbol{C}$. arcuata, eliminando 100\% das larvas. As estirpes CG 79, CG 61, CG 224, CG 218, CG 225 e CG 253, apesar de eliminarem de 50 até 87,5\% das larvas, não diferiram significativamente da testemunha (Figura 1). As duas estirpes de $\boldsymbol{M}$. anisopliae CG 210 e CG 321 eliminaram 80 e $100 \%$ das larvas de $\boldsymbol{C}$. arcuata, respectivamente, sendo a fase larval do inseto susceptível a ambas (Figura 2). A aplicação no solo e em sementes do conjunto de estirpes de $\boldsymbol{B}$. bassiana e M. anisopliae avaliado neste experimento reduziu os danos provocados pelas larvas de $\boldsymbol{C}$. arcuata e beneficiou o rendimento de grãos de feijoeiro no campo (TEIXEIRA, 1998). Resultados semelhantes foram 


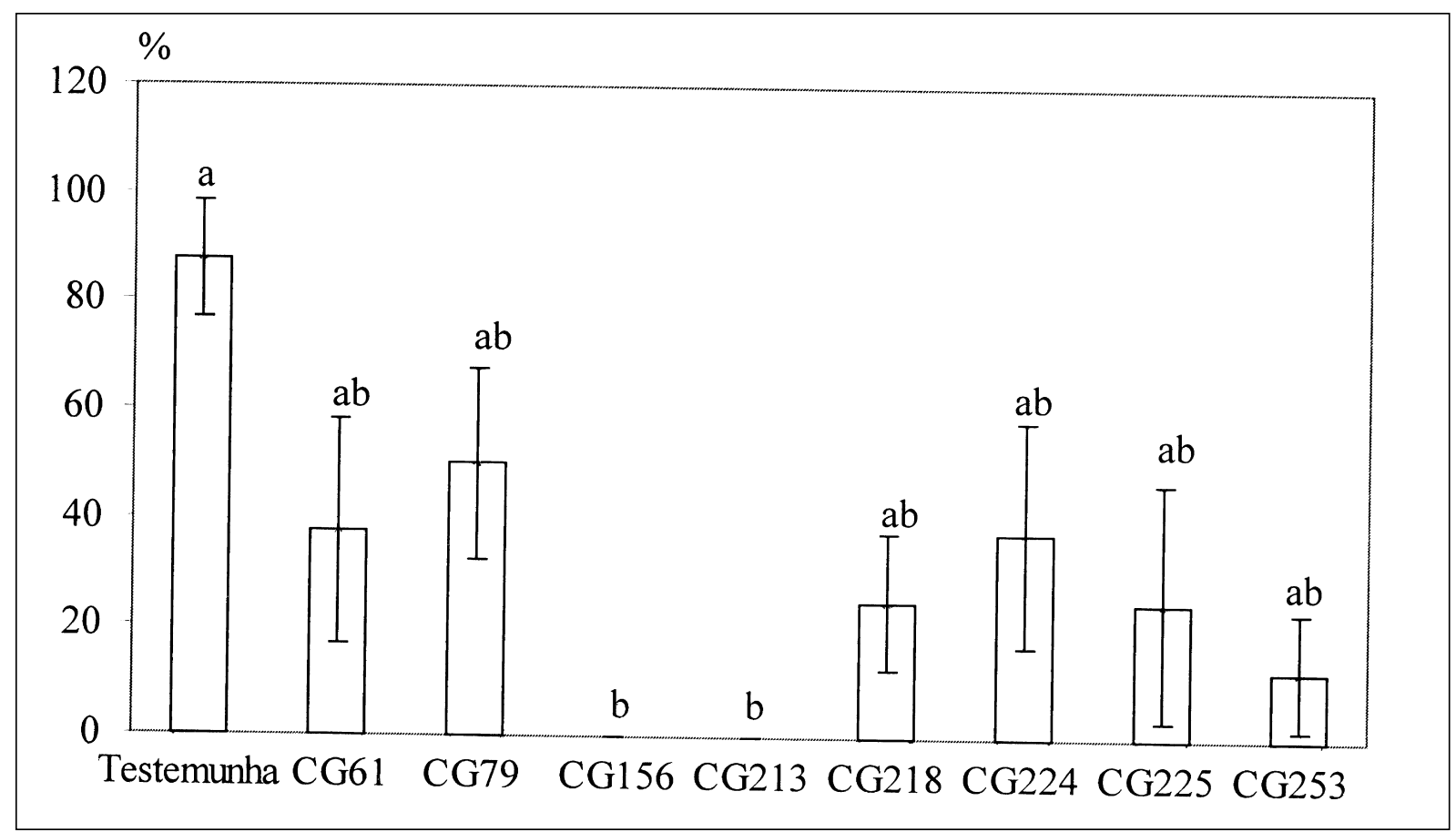

Figura 1 - Efeito de $\boldsymbol{B}$. bassiana na sobrevivência de larvas de $\boldsymbol{C}$. arcuata. Médias seguidas pela mesma letra não diferem entre si pelo teste de Tukey $(\mathrm{P}=0,05)$.

obtidos em casa-de-vegetação através da pulverização de quatro isolados de $\boldsymbol{B}$. bassiana e quatro isolados de $\boldsymbol{M}$. anisopliae no solo em doses equivalentes a 500 e 1.000 g de conídios / ha ou de sua aplicação nas sementes em doses equivalentes a 250 e 500 g de conídios / $60 \mathrm{~kg}$ de sementes, tendo sido os isolados eficientes no controle de larvas de 1ํinstar de $\boldsymbol{C}$. arcuata (QUINTELA et al. 1990). A patogenicidade das estirpes CP 1 e CP 7 de B. bassiana e E 6 e Phil 7 de M. anisopliae para larvas de $\boldsymbol{C}$. arcuata também foi confirmada pela aplicação dos isolados na superfície do solo, junto ao colo de plantas de caupi (SÁ et al., 1989). A estirpe de B. bassiana FHD 13 destacou-se em bioensaio entre dezesseis isolados de fungos, causando a mortalidade

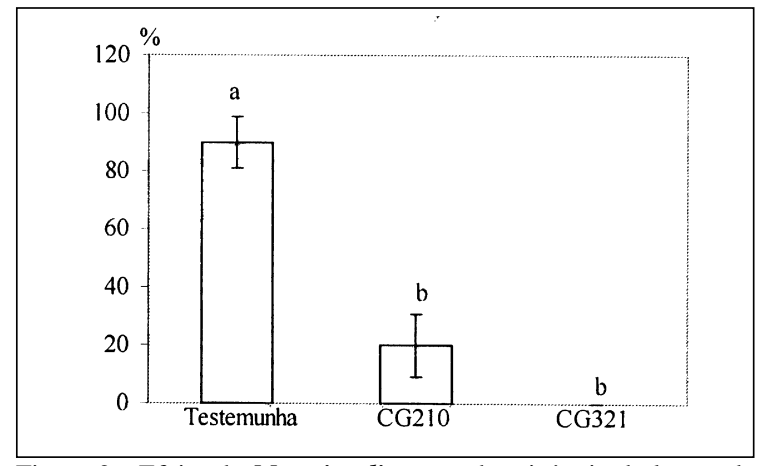

Figura 2 - Efeito de $\boldsymbol{M}$. anisopliae na sobrevivência de larvas de C. arcuata. Médias seguidas pela mesma letra não diferem entre si pelo teste de Tukey $(P=0,05)$. de até $70 \%$ das larvas de $3^{\circ}$ instar de $\boldsymbol{D}$. speciosa Germar (CONSOLO et al. 2003). A aplicação de B. bassiana e M. anisopliae no solo reduziu a emergência de adultos e os danos causados por larvas de $\boldsymbol{D}$. undecimpunctata Howardi às raízes de milho (Zea mays L.), sendo que a concentração estável de 2,7 x $10^{5}$ UFC (unidades formadoras de colônia) de $\boldsymbol{M}$. anisopliae / $\mathrm{cm}^{3}$ de solo preveniu os danos provocados pelas larvas aos coletos e raízes e evitou a emergência de adultos, comparandose à testemunha sem inseto (KRUEGER \& ROBERTS, 1997).

A utilização de estirpes de fungos isoladas de Cerotoma sp. ou de outros crisomelídeos pode ter favorecido a susceptibilidade das larvas aos isolados testados. GARCIA et al. (1999) avaliaram a toxidade de dez estirpes de B. bassiana para larvas de Epilachna varivestis (Mulsant) (Coleoptera: Coccinellidae) e constataram que as estirpes provenientes de coleópteros foram mais tóxicas do que as isoladas de insetos de outras ordens.

As estirpes de B. thuringiensis CG 904, CG 946 e CG 948 reduziram em até 30\% o número de larvas de $\boldsymbol{C}$. arcuata, sem diferir da testemunha (Figura 3). A variação natural verificada por SIEGFRIED et al. (2005) na susceptibilidade de larvas provenientes de gerações e populações distintas de $\boldsymbol{D}$. virgifera virgifera LeConte à toxina de $\boldsymbol{B}$. thuringiensis, provavelmente, foi limitada pela utilização de larvas de $\boldsymbol{C}$. arcuata provenientes de mesmas população e geração. 


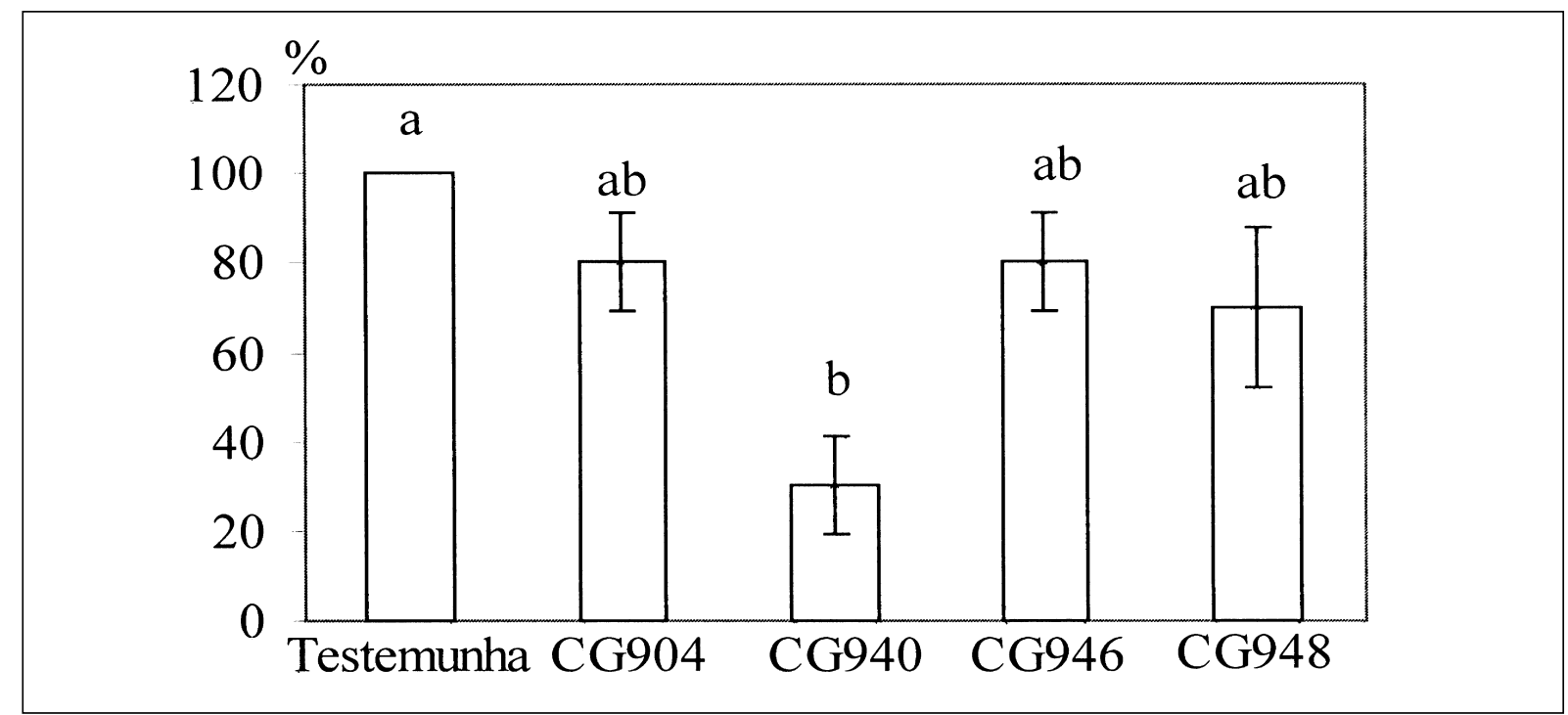

Figura 3 - Efeito de $\boldsymbol{B}$. thuringiensis na sobrevivência de larvas de $\boldsymbol{C}$. arcuata. Médias seguidas pela mesma letra não diferem entre si pelo teste de Tukey $(\mathrm{P}=0,05)$.

A estirpe de $\boldsymbol{B}$. thuringiensis CG 940 foi patogênica para $70 \%$ das larvas de $\boldsymbol{C}$. arcuata (Figura 3), cujo pH intestinal está na faixa de seis a sete, sendo considerada eficiente para o seu controle. Apesar de o $\mathrm{pH}$ intestinal alcalino ter sido considerado por alguns autores como determinante para a susceptibilidade das larvas de insetos ao $\boldsymbol{B}$. thuringiensis (WILSON \& BENOIT, 1993), estudos posteriores da interação entre a delta-endotoxina Cry 1C e as vesículas fosfolipídicas revelaram que a capacidade da toxina de aumentar a permeabilidade da membrana foi incrementada quando o pH do meio era menor do que cinco (BUTKO et al., 1994). Cristais de B. thuringiensis var. san diego dissolveram em $\mathrm{pH}$ maior que 10 e menor que 4, sendo que a solubilização em $\mathrm{pH}$ ácido foi mais lenta, porém com a mesma eficiência. Além disso, a toxidade das soluções ácida e alcalina para a larva de $3^{\circ}$ instar de Crysomela scripta Fabricius foi igual (KOLLER et al., 1992), indicando que um valor de $\mathrm{pH}$ não-alcalino do intestino do inseto não impede que o inseto seja susceptível ao B. thuringiensis.

D. speciosa apresenta $\mathrm{pH}$ intestinal considerado baixo para a expressão da delta-endotoxina, estando este na faixa entre cinco e seis (SILVAWERNECK et al. 1995). Entretanto, a susceptibilidade de Diabrotica spp. às toxinas de $\boldsymbol{B}$. thuringiensis é amplamente estudada. Experimentos avaliam a expressão de novas delta-endotoxinas em milho transgênico (MOELLENBECK et al., 2001; AL-DEEB \& WILDE, 2005), variações mais letais das toxinas (VAUGHN et al., 2005), mecanismos responsáveis pela seletividade da toxina para $\boldsymbol{D}$. undecimpunctata
(GALITSKY et al., 2001), assim como os efeitos em insetos não-alvos (AL-DEEB \& WILDE, 2003). Esses exemplos indicam que a faixa neutra de $\mathrm{pH}$ do intestino das larvas de $\boldsymbol{C}$. arcuata não impede que o inseto seja controlado com o patógeno $\boldsymbol{B}$. thuringiensis, como verificado neste experimento pela mortalidade causada pela estirpe CG 940. A eficácia de B. thuringiensis no controle de $\boldsymbol{C}$. ruficornis em batata no campo foi confirmada pela paralização de larvas e adultos ocorrida uma hora após a aplicação de uma suspensão de 1,4 g de esporos / L, resultando em ganhos de 32\% no rendimento da cultura (AMBANG et al., 2002)

\section{CONCLUSÕES}

Os isolados CG 156 e CG 213 de B. bassiana e CG 321 de $\boldsymbol{M}$. anisopliae causaram maior mortalidade de larvas de $\boldsymbol{C}$. arcuata, sendo mais eficientes no controle deste inseto do que todos os isolados de $\boldsymbol{B}$. thuringiensis testados.

A susceptibilidade de larvas de $\boldsymbol{C}$. arcuata a isolados de B. bassiana, M. anisopliae e $\boldsymbol{B}$. thuringiensis selecionados em bioensaios mostra perspectivas promissoras para seu uso no solo, em condições de campo.

\section{AGRADECIMENTOS}

À Coordenação de Aperfeiçoamento de Pessoal de Nível Superior (CAPES) e ao Conselho Nacional de Desenvolvimento Científico e Tecnológico (CNPq), pelo suporte financeiro durante a execução do trabalho. A Bruno Rezende Silva, pela revisão do abstract. 


\section{REFERÊNCIAS}

ABReU Neto, J.R.M.V. Produção de ovos de Cerotoma arcuata (Olivier) (Coleoptera: Chrysomelidae) efeito de cor de substrato e fotoperíodo. 1999. 52f. Dissertação (Mestrado em Entomologia) - Curso de Pós-graduação em Entomologia, Universidade Federal de Viçosa.

AL-DEEB, M.A.; WILDE, G.E. Effect of Bt corn expressing the Cry3Bb1 toxin on western corn rootworm (Coleoptera: Chrysomelidae) biology. Journal of the Kansas Entomological Society, Lawrence, v.78, n.2, p.142-152, 2005.

AL-DEEB, M.A.; WILDE, G.E. Effect of Bt corn expressing the Cry3Bb1 toxin for corn rootworm control on aboveground nontarget arthropods. Environmental Entomology, Lanham, v.32, n.5, p.1164-1170, 2003.

ALVES, S.B. Controle microbiano de insetos. 2.ed. São Paulo: Fealq, 1998. 1168p.

ALVES, S.B.; MORAES, S.A. Quantificação de inoculo de patógenos de insetos. In: ALVES, S.B. Controle microbiano de insetos. 2.ed. Piracicaba: Fealq, 1998. p.765-777.

AMBANG, Z. et al. Evaluation de l'efficacité de la Bacillus thuringiensis contre les larves et imagos de Andrector ruficornis sur des plants de Solanum tuberosum au Cameroun. Tropicultura, Brussels, v.20, n.3, p.113-117, 2002.

BUTKO, P. et al. Membrane interactions and surface hydrophobicity of Bacillus thuringiensis $\delta$-endotoxin CryIC. FEBS Letters, Amsterdam, v.340, p.89-92, 1994.

CARDONA, C. et al. Evaluation of damage to common beans by larvae and adults of Diabrotica balteata and Cerotoma facialis. Journal of Economic Entomology, Lanham, v.75, n.2, p.324-327, 1982.

CONSOLO, V.F. et al. Pathogenicity, formulation and storage of insect pathogenic hyphomycetous fungi tested against Diabrotica speciosa. BioControl, Dordrecht, v.48, n.6, p.705712, 2003.

COOPER, S.G. et al. Combining genetic engineering and traditional breeding to provide elevated resistance in potatoes to Colorado potato beetle. Entomologia Experimentalis et Applicata, Oxford, v.112, n.1, p.37-46, 2004.

GALITSKY, N. et al. Structure of the insecticidal bacterial delta-endotoxin Cry3Bb1 of Bacillus thuringiensis. Acta Cristallographica, Copenhagen, v.57, n.8, p.1101-1109, 2001.

GARCIA, G.C. et al. Toxicological assessment of Beauveria bassiana against Mexican bean beetle (Coleoptera: Coccinellidae). Southwestern Entomologist, Dallas, v.24, n.3, p.255-259, 1999.

HEINECK, M.A.; CORSEUIL, E. Ciclo vital e consumo alimentar de adultos de Cerotoma arcuata tingomariana Bechyné (Coleoptera: Chrysomelidae) em soja. Anais da Sociedade Entomológica do Brasil, Jaboticabal, v.24, n.3, p.579-586, 1995.
KOLLER, C.N. et al. Characterization of the $\mathrm{pH}$ mediated solubility of Bacillus thuringiensis var. san diego native deltaendotoxin crystals. Biochemical and Biophysical Research Communications, San Diego, v.184, n.2, p.692-699, 1992.

KRIEG, A. Interactions between pathogens. In: BURGES, H.D.; HUSSEY, N.W. Microbial control of insects and mites. London: Academic, 1971. p.459-467.

KRUEGER, S.R.; ROBERTS, D.W. Soil treatment with entomopathogenic fungi for corn rootworm (Diabrotica spp.) larval control. Biological Control, Orlando, v.9, n.1, p.6774, 1997.

LAYTON, B.M. The effects of feeding by bean leaf beetle larvae, Cerotoma trifurcata (Foster), on nodulation and nitrogen fixation of soybeans. 1983. 105f. Tese (Mestrado em Entomologia) - Curso de Pós-graduação em Entomologia, Louisiana State University.

LORD, J.C. et al. Effects of the fungus Beauveria bassiana (Bal.) Vuill behavior, oviposition, and susceptibility to secundary infections of adult Cerotoma arcuata (Olivier, 1791) (Coleoptera: Chrysomelidae). Anais da Sociedade Entomológica do Brasil, Jaboticabal, v.16, n.1, p.187-197, 1987.

MARQUEZ, A.M. Seleção e caracterização de estirpes de Bacillus thuringiensis contendo genes tipo Cry III tóxicas para Tenebrio molitor (Coleoptera: Tenebrionidae). 1996. 117f. Dissertação (Mestrado em Biologia Molecular) - Curso de Pós-graduação em Ciências Biológicas, Universidade de Brasília.

MOELLENBECK, D.J. et al. Insecticidal proteins from Bacillus thuringiensis protect corn from corn rootworms. NatureBiotechnology, New York, v.19, n.7, p.668-672, 2001.

NAVA, E.D. et al. Danos causados por diferentes densidades de larvas de Cerotoma arcuatus em plantas de soja. Pesquisa Agropecuária Brasileira, Brasília, v.38, n.10, p.1217-1222, 2003.

QUINTELA, E.D. et al. Principais pragas do caupi no Brasil. Goiânia: Embrapa-Cnpaf, 1991. 38p. (Documentos, 35).

QUINTELA, E.D.et al. Patogenicidade de Beauveria bassiana e Metarhizium anisopliae a Cerotoma arcuata Olivier (Coleoptera: Chrysomelidae) e Elasmopalpus lignosellus Zeller (Lepdoptera: Pyralidae). In: REUNIÃO NACIONAL DE PESQUISA DE FEIJÃO, 3., 1990, Vitória, ES. Resumos... Vitória: Empresa Capixaba de Pesquisa Agropecuária, 1990. n.39.

RAJNAUTH, G.L. et al. Laboratory rearing of Cerotoma arcuata (Oliv.), a beetle vector of cowpea severe mosaic virus. Tropical Agriculture, Trinidad, v.64, n.3, p.191-192, 1987.

SÁ, G.S. de et al. Patogenicidade de Beauveria bassiana e Metarhizium anisopliae às larvas de Cerotoma arcuata (Coleoptera: Chrysomelidae) no solo. In: CONGRESSO BRASILEIRO DE ENTOMOLOGIA, 12., 1989, Belo Horizonte, MG. Resumos... Belo Horizonte: Sociedade Entomológica do Brasil, 1989. v.1, 263p. p.225. 
SALAS, F.J.S et al. Tentativas de transmissão de um isolado do vírus do mosaico severo do caupi (CpSMV-SP) por artrópodos, em laboratório. Scientia Agrícola, Piracicaba, v.56, p.413420, 1999.

SIEGFRIED, B.D. et al. Baseline susceptibility of western corn rootworm (Coleoptera: Crysomelidae) to Cry3Bb1 Bacillus thuringiensis toxin. Journal of Economic Entomology, Lanham, v.98, n.4, p.1320-1324, 2005.

SILVA-WERNECK, J.O. et al. Técnica de criação de Diabrotica speciosa (Germ.) (Coleoptera: Chrysomelidae) para bioensaios com bacilos e fungos entomopatogênicos. Anais da Sociedade Entomológica do Brasil, Jaboticabal, v.24, n.1, p.45-52, 1995.

TEIXEIRA, M.L.F. Efeito da cobertura morta e da aplicação de Metarhizium anisopliae (Metsch) Sorokin, Beauveria bassiana (Bals.) Vuillemin e Bacillus thuringiensis Berliner, no controle biológico de Cerotoma arcuata Olivier (Coleoptera: Chrysomelidae) em feijoeiro. 1998. 126f. Tese (Doutorado em Ciência do Solo, Biologia do Solo) - Curso de Pós-graduação em Agronomia, Universidade Federal Rural do Rio de Janeiro.

TEIXEIRA, M.L.F. et al. Effects of Cerotoma arcuata (Coleoptera: Chrysomelidae) on the predation of nodules and on $\mathrm{N}_{2}$-fixation of Phaseolus vulgaris. Journal of Economic Entomology, Lanham, v.89, p.165-169, 1996.

TEIXEIRA, M.L.F. Efeito de Cerotoma arcuata Olivier (Coleoptera: Chrysomelidae) na fixação biológica de nitrogênio em feijoeiro (Phaseolus vulgaris L.). 1993. $176 f$. Tese (Mestrado em Ciência do Solo - Biologia do Solo) - Curso de Pós-graduação em Agronomia, Universidade Federal Rural do Rio de Janeiro.

VAUGHN, T. et al. A method of controlling corn rootworm feeding using Bacillus thuringiensis protein expressed in transgenic maize. Crop-Science, Madison, v.45, n.3, p.931938, 2005.

WILSON, G.R.; BENOIT, T.G. Alkaline pH activates Bacillus thuringiensis spores. Journal of Invertebrate Pathology, San Diego, v.62, p.87-89, 1993.

YAGINUMA, K. et al. Isolation and use of entomogenous fungi in the Cerrados for the control of insect pests. Planaltina: Embrapa-Cpac, 1994. p.215-225. (Relatório Técnico do Projeto Nipo-Brasileiro de Cooperação em Pesquisa Agrícola). 